\title{
Case Report: Iliopsoas Hematoma during the Clinical Course of Severe COVID-19 in Two Male Patients
}

\author{
Hideta Nakamura, ${ }^{1 \star}$ Gen Ouchi, ${ }^{2}$ Kazuya Miyagi, ${ }^{1}$ Yuuri Higure, ${ }^{1}$ Mariko Otsuki, ${ }^{1}$ Naoya Nishiyama, ${ }^{1}$ Takeshi Kinjo, ${ }^{1}$ \\ Masashi Nakamatsu, ${ }^{1}$ Masao Tateyama, ${ }^{1}$ Ichiro Kukita, ${ }^{2}$ and Jiro Fujita ${ }^{1}$ \\ ${ }^{1}$ Department of Infectious, Respiratory and Digestive Medicine, Graduate School of Medicine, University of the Ryukyus, Okinawa, Japan; \\ ${ }^{2}$ Department of Emergency and Critical Care Medicine, Graduate School of Medicine, University of the Ryukyus, Okinawa, Japan
}

\begin{abstract}
Anticoagulation plays a major role in reducing the risk of systematic thrombosis in patients with severe COVID-19. Serious hemorrhagic complications, such as intracranial hemorrhage, have also been recognized. However, intra-abdominal hemorrhage is under-recognized because of its rare occurrence, despite high mortality. Here, we discuss two cases of spontaneous iliopsoas hematoma (IPH) likely caused by anticoagulants during the clinical course of COVID19. We also explored published case reports to identify clinical characteristics of IPH in COVID-19 patients. The use of anticoagulants may increase the risk of lethal IPH among COVID-19 patients becsuse of scarce data on optimal dosage and adequate monitoring of anticoagulant effects. Rapid diagnosis and timely intervention are crucial to ensure good patient outcomes.
\end{abstract}

\section{INTRODUCTION}

As awareness of COVID-19-associated coagulopathy increases, thrombotic manifestations are implicated in mortality. ${ }^{1,2} \mathrm{~A}$ recent multicenter retrospective study from the United States reported a thrombotic complication rate was $9.5 \%$, despite standard prophylactic anticoagulation dose. ${ }^{3}$ Furthermore, hemorrhagic events among COVID-19 patients have been recognized. The overall proportion of patients with bleeding complications range from $4.8 \%$ to $8 \%$, of which approximately $3.5 \%$ had major bleeding. ${ }^{3,4}$

Herein, we describe two cases of life-threatening iliopsoas hematoma (IPH) during the clinical course of COVID-19. Both cases were recovering from acute respiratory distress syndrome owing to COVID-19 when they developed IPH. Moreover, they were receiving anticoagulants to prevent thrombosis. This report highlights IPH as a serious hemorrhagic complication in severe COVID-19 patients treated with anti-thrombotic agents.

\section{CASE REPORT}

Case 1. A 62-year-old man was referred to our institution because of a 4-day history of fever, productive cough, and fatigue. Results of real-time PCR for SARS-CoV-2 performed for a nasal swab were positive.

On admission, his temperature was $37.2^{\circ} \mathrm{C}$; blood pressure, 148/76 mmHg; heart rate, 100 beats/minute; respiratory rate, 24 breaths/minute; oxygen saturation $\left(\mathrm{SpO}_{2}\right), 91-94 \%$ in ambient air; and ratio of arterial oxygen partial pressure to fractional inspired oxygen (P/F ratio), 316. Chest computed tomography (CT) on admission revealed ground-glass opacities in the bilateral peripheral lung fields, and laboratory findings were leukocyte count, 6.8 (normal, 3.3-8.6) $\times 10^{9} / \mathrm{L}$ with $76.9 \%$ neutrophils; lymphocyte percentage, $18.3 \%$ (normal, 26-46\%); platelet count, 178 (normal, 158-348) $\times$ $10^{3} / \mu \mathrm{L}$; interleukin-6 level, $89.1 \mathrm{pg} / \mathrm{mL}$ (cutoff $<4.0 \mathrm{pg} / \mathrm{mL}$ );

\footnotetext{
*Address correspondence to Hideta Nakamura, Department of Infectious, Respiratory and Digestive Medicine, Graduate School of Medicine, University of the Ryukyus, 207 Uehara, Nishihara-cho, Okinawa 903-0215, Japan. E-mail: hnnakamu@med.u-ryukyu.ac.jp
}

C-reactive protein (CRP) level, $5.53 \mathrm{mg} / \mathrm{dL}$ (cutoff $<0.14$ $\mathrm{mg} / \mathrm{dL}$ ); ferritin level, 537.1 (normal, 50-200) ng/mL; D-dimer level, $0.5 \mu \mathrm{g} / \mathrm{mL}$ (cutoff $<1.0 \mu \mathrm{g} / \mathrm{mL}$ ); and fibrinogen level, 611 (normal, 180-350) mg/dL.

We prescribed favipiravir (loading dose of $1,800 \mathrm{mg}$ on day 1 , followed by $400 \mathrm{mg}$ twice daily for 13 days), dexamethasone (6.6 mg/day intravenously administered for 10 days), and nafamostat $(100 \mathrm{mg} /$ day). Despite initial treatment, $10 \mathrm{~L}$ of oxygen supplementation was required to maintain $\mathrm{SpO}_{2}$ $>90 \%$ for the first 3 days after admission. Hence, tocilizumab ( $8 \mathrm{mg} / \mathrm{kg}$ ) was intravenously administered on days 3 and 4 . Hypoxia continued to worsen; thus, the patient was intubated and transferred to the intensive care unit (ICU). Recombinant human soluble thrombomodulin (rhsTM; 12,800 U twice daily) was administered to prevent thrombosis. After 5 days in the ICU, he fully recovered from acute respiratory failure, extubated, and returned to the ward on day 9. On the same day, rhsTM was replaced with daily subcutaneous enoxaparin (40 mg).

On day 14 , the patient complained about severe and sudden pain in his left lower back after physiotherapy. His blood pressure and pulse rates were $118 / 86 \mathrm{mmHg}$ and 115 beats/ minute, respectively. Hemoglobin levels dropped from 15.7 $\mathrm{g} / \mathrm{dL}$ to $13.2 \mathrm{~g} / \mathrm{dL}$ with an elevated $D$-dimer level of $2.6 \mu \mathrm{g} / \mathrm{mL}$. Contrast-enhanced abdominal and pelvic CT showed a hematoma $(6.5 \times 10.5 \mathrm{~cm})$ in the left iliopsoas muscle spreading to the retroperitoneal space with extravasation (Figure 1A). Urgent transarterial embolization (TAE) was performed by interventional radiologists. Extravasation was identified from the left L3 and L4 lumbar arteries and common iliac arteries. Those arteries were selectively catheterized with a five French Mickelson catheter through which gelatin sponge particles were placed for occlusion. After the procedure, no active contrast extravasation was observed. He received six packed red blood cell (PRBC) units with intravenous fluids because his hemoglobin levels dropped to $7.5 \mathrm{~g} / \mathrm{dL}$. He was discharged from the hospital with improved hemoglobin levels $(12.6 \mathrm{~g} / \mathrm{dL})$ on day 33.

Case 2. A 79-year-old man presented with fever and general fatigue for 2 days and was transferred to our hospital owing to COVID-19-associated acute respiratory distress syndrome. A different general hospital administered favipiravir, dexamethasone, 

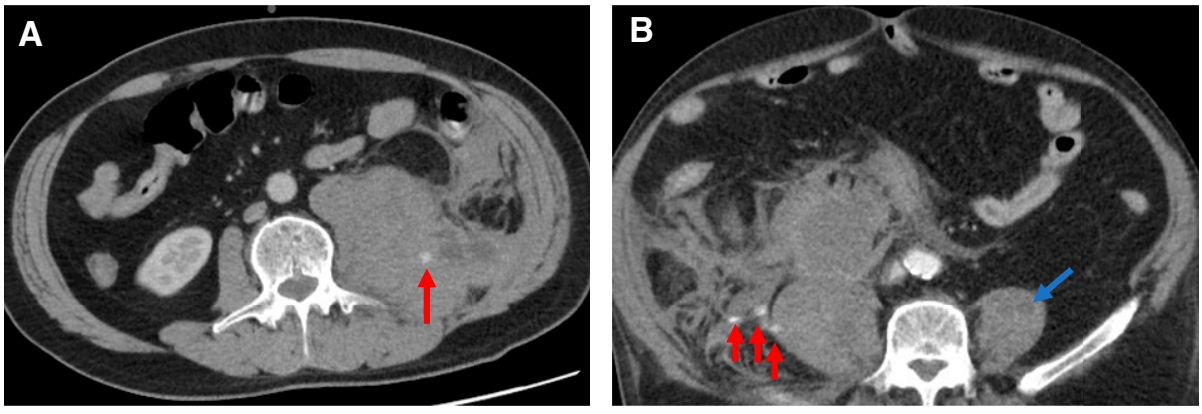

FIGURE 1. Contrast-enhanced computed tomography of the abdomen and pelvis. (A) Case 1: A massive hematoma with extravasation (red arrow) in the left iliopsoas muscle spreading to the retroperitoneal space is observed. (B) Case 2: The swollen right iliopsoas muscle with retroperitoneal hematoma and extravasation is observed (red arrow). A small low-density area (blue arrow) in the left iliopsoas muscle suggests a hematoma.

and subcutaneous unfractionated heparin (UFH) on referral day. Nevertheless, respiratory failure progressively worsened, and he was intubated.

Oxygen saturation was $95 \%$ under fraction of inspired oxygenation, 50\%; P/F ratio 167; blood pressure, 132/65 mmHg; heart rate, 40 beats/minute; temperature, $38.4^{\circ} \mathrm{C}$ at the time of admission to our hospital. Initial laboratory findings were leukocyte count, $10.2 \times 10^{9} / \mathrm{L}$ with $89.7 \%$ neutrophils; lymphocyte percentage, $5.6 \%$; platelet count, $129 \times 10^{3} / \mu \mathrm{L}$; CRP level, $2.9 \mathrm{mg} / \mathrm{dL} ; D$-dimer level, $0.6 \mu \mathrm{g} / \mathrm{mL}$; and fibrinogen level, $285 \mathrm{mg} / \mathrm{dL}$. Chest CT revealed bilateral ground-glass opacities with a small amount of pleural effusion.

Remdesivir (loading dose of $200 \mathrm{mg}$ on day 1, followed by $100 \mathrm{mg}$ once daily for 10 days), methylprednisolone $(1,000 \mathrm{mg}$ for 3 days) followed by dexamethasone ( $6.6 \mathrm{mg}$ for 7 days), nafamostat (100 mg/day), and intravenous tocilizumab (two consecutive doses, $8 \mathrm{mg} / \mathrm{kg}$ ) were administered. Intravenous UFH was also administered, with the dosage adjusted to meet the target-activated partial thromboplastin time (aPTT) range of 1.5-2.5 times the control value. The P/F ratio increased from 167 to 290 on day 10, and he was extubated.

After extubation, blood pressure gradually decreased with tachycardia. Moreover, he complained of gradual worsening pain in the right lower back since extubation. His hemoglobin levels decreased from $12.2 \mathrm{~g} / \mathrm{dL}$ to $9.7 \mathrm{~g} / \mathrm{dL}$, suggesting hemorrhagic hypovolemic shock. His platelet count was $158 \times$ $10^{3} / \mu \mathrm{L}$; aPTT, 42.1 (normal, 23.5-35) seconds; $D$-dimer level, $2.2 \mu \mathrm{g} / \mathrm{mL}$; and fibrinogen level, $167 \mathrm{mg} / \mathrm{dL}$. Contrastenhanced abdominal CT showed swelling of the right iliopsoas muscle with retroperitoneal hematoma, extravasation in the right psoas major muscle, and a small-density area in the left psoas major muscle (Figure 1B). Intravenous UFH infusion was immediately discontinued; TAE was urgently attempted with rapid volume replacement and four units of PRBC transfusion. However, he had cardiac arrest for 4 minutes during preoperative preparations. Although he responded to resuscitation, the second episode of cardiac arrest occurred within an hour. Because his family members did not want further resuscitation attempts, 18 hours after extubation, his death was confirmed.

\section{DISCUSSION}

The current case series showed the life-threatening IPH in two COVID-19 patients on either prophylactic or therapeutic dose of anticoagulants; whereas one patient was successfully treated with TAE, the other patient died because of hemorrhagic hypovolemic shock.

lliopsoas hematoma is defined as retroperitoneal hemorrhage involving the iliopsoas muscle. The incidence of spontaneous IPH during hospitalization ranges from $0.3 \%$ to $0.4 \% .^{5,6}$ The precise frequency of spontaneous IPH in COVID-19 patients remains unclear; however, eight case series have been reported (Table 1). ${ }^{7-13}$ Several specific predisposing factors, including anticoagulation therapy, advanced age, and hemodialysis, are associated with developing spontaneous $\mathrm{IPH} .{ }^{5}$ Previous reports in addition to the current case series were consistent with this evidence. Furthermore, concurrent off-level use of rhsTM or nafamostat mesylate may have contributed to major bleeding events in our cases. Despite insufficient data, those agents had been administered as compassionate therapy to alleviate hypercoagulation and for their antiviral effects. ${ }^{14,15}$

Apart from anticoagulants, microvascular vulnerability derived from atherosclerosis and microtrauma, including cough, could lead to retroperitoneal bleeding; however, pathology has not confirmed the hypothesis. ${ }^{5}$ Whether direct effects of SARSCoV-2 on vascular endothelial cells cause hemorrhage events is uncertain. However, several hypotheses have been raised: the affinity of SARS-CoV-2 for angiotensin-converting enzyme 2 receptors on endothelial cells can directly damage vessels, causing vessel wall rupture. ${ }^{16}$ By contrast, renin-angiotensinaldosterone system dysregulation may contribute to increased blood pressure, causing hemorrhagic events. ${ }^{16}$ Erdinc and Raina ${ }^{9}$ reported a COVID-19 patient who developed IPH without anticoagulants.

The mortality rate of patients with spontaneous IPH, which occurred during hospitalization, is estimated to be between $30 \%$ and $50 \% .^{5,6}$ Given the high mortality rate, physicians should pay careful attention to the disease's early signs. Thrombocytopenia (platelet count $<150 \times 10^{3}$ cells $/ \mu \mathrm{L}$ ) and elevated $D$-dimer levels $(>2.5 \mu \mathrm{g} / \mathrm{mL})$ at initial presentation are predictive of hemorrhagerelated complications during hospitalization. ${ }^{3}$ In fact, the initial platelet count in case 2 was $129 \times 10^{3}$ cells $/ \mu \mathrm{L}$.

One-third of patients with spontaneous IPH can present with Lenk's triad: severe flank pain, hemodynamic shock, and palpable mass. ${ }^{17}$ Monitoring the effects of anticoagulants is imperative to minimize the risk of hemorrhagic events; however, there are some inherent issues. Artzer et al. ${ }^{6}$ reported that severe adverse events could occur among patients treated with UFH despite optimal aPTT values. For case 2, aPTT values were within the target range. Regarding low-molecular-weight heparin, anti-factor Xa activity and thromboelastography may not 
TABLE 1

Summary of case reports on iliopsoas hematoma in patients with COVID-19

\begin{tabular}{|c|c|c|c|c|c|c|c|c|c|}
\hline $\begin{array}{l}\text { Case } \\
\text { no. }\end{array}$ & Reference & $\begin{array}{c}\text { Age, } \\
\text { years }\end{array}$ & Sex & Preexisting condition & $\begin{array}{l}\text { Severity of } \\
\text { COVID- } 19^{\star}\end{array}$ & Anticoagulation at hemorrhage & $\begin{array}{c}\text { Intervention for } \\
\text { hemorrhage }\end{array}$ & Outcome & Comments \\
\hline 1. & Patel et al. ${ }^{7}$ & 69 & $\mathrm{M}$ & CAD, HTN, and type 2 DM & Severe & $\begin{array}{l}\text { Therapeutic enoxaparin } \\
(1 \mathrm{mg} / \mathrm{kg})\end{array}$ & TAE & Alive & - \\
\hline 2. & $\begin{array}{l}\text { Scialpi } \\
\text { et al. }^{8}\end{array}$ & 57 & M & $\begin{array}{l}\text { Non-Hodgkin's } \\
\text { lymphoma }\end{array}$ & ND & ND & TAE & Alive & - \\
\hline 3. & $\begin{array}{l}\text { Erdinc and } \\
\text { Raina }^{9}\end{array}$ & 58 & $\mathrm{~F}$ & HTN, obesity (BMl, 62 kg/m²) & Severe & None & ND & Died & Acute DVT coincided \\
\hline 4. & Guo et al. ${ }^{10}$ & 71 & $\mathrm{M}$ & ND & Critical & $\begin{array}{l}\mathrm{ND} \text {, but presumably on } \\
\text { anticoagulants } \\
\text { because of ECMO }\end{array}$ & TAE & Alive & On ECMO \\
\hline 5. & $\begin{array}{l}\text { Angileri } \\
\text { et al. }{ }^{11}\end{array}$ & 59 & $\mathrm{M}$ & ND & Critical & $\begin{array}{l}\text { Prophylactic enoxaparin } \\
\text { (60 mg/day) }\end{array}$ & ND & ND & - \\
\hline 6. & $\begin{array}{l}\text { Conti } \\
\text { et al. }{ }^{12}\end{array}$ & 76 & M & CAD and HTN & Severe & $\begin{array}{l}\text { Prophylactic LMWH (6,000 } \\
\text { Ul/day) }\end{array}$ & TAE & ND & - \\
\hline 7. & $\begin{array}{l}\text { Conti } \\
\text { et al. }{ }^{12}\end{array}$ & 72 & $\mathrm{~F}$ & HTN & Severe & $\begin{array}{l}\text { Therapeutic LMWH (100 } \\
\text { UI/kg/bid) }\end{array}$ & TAE & ND & Acute DVT coincided \\
\hline 8. & $\begin{array}{l}\text { Bargellini } \\
\text { et al. }{ }^{13}\end{array}$ & 71 & M & Atrial fibrillation & & $\begin{array}{l}\text { Prophylactic LMWH } \\
\quad(6,000 \mathrm{UI} / 12 \text { hours })\end{array}$ & TAE & Alive & \\
\hline 9. & Case 1 & 62 & $\mathrm{M}$ & None & Critical & $\begin{array}{l}\text { Prophylactic enoxaparin } \\
\text { (40 mg bid } \\
\text { subcutaneous } \\
\text { injection) }\end{array}$ & TAE & Alive & \\
\hline 10. & Case 2 & 79 & $\mathrm{M}$ & $\begin{array}{l}\text { HTN, obesity (BMI, } 34.2 \\
\text { kg/m²), type } 2 \text { DM }\end{array}$ & Critical & $\begin{array}{l}\text { Therapeutic } \\
\text { unfractionated heparin }\end{array}$ & TAE & Died & $\begin{array}{l}\text { Died because of } \\
\text { hypovolemic shock }\end{array}$ \\
\hline
\end{tabular}

bid = bis in die; $\mathrm{BMI}=$ body mass index; $\mathrm{CAD}=$ coronary artery disease; $\mathrm{DM}=$ diabetes; $\mathrm{DVT}=$ deep venous thrombosis; $\mathrm{ECMO}=$ extracorporeal membrane oxygenation; $\mathrm{F}=$ female; $\mathrm{HTN}=$ hypertension; $\mathrm{LMWH}=$ low-molecular-weight heparin; $\mathrm{M}=$ male; $\mathrm{ND}=$ not described; $\mathrm{TAE}=$ transarterial embolization.

${ }^{\star}$ Severity of COVID-19 was defined as follows. Severe: individuals who have oxygen saturation $<94 \%$ on ambient air, a ratio of arterial partial pressure of oxygen to fraction of inspired oxygen $<300 \mathrm{mmHg}$, respiratory frequency $>30$ breaths/minute, or lung infiltrates $>50 \%$. Critical: individuals who have respiratory failure, septic shock, and/or multiple organ dysfunction.

be reliable for monitoring. ${ }^{18}$ Contrast-enhanced CT plays an important role in diagnosis, providing a wide range of information on volume, spatial extent, and compressive complications or extravasation. ${ }^{5}$

An effective anticoagulation therapy with low risk of bleeding is urgently required. Despite the lack of data, some experts have suggested intensified anticoagulation strategy such as using enoxaparin ( $0.5 \mathrm{mg} / \mathrm{kg}$ twice daily) because standard-dose prophylaxis may not prevent thrombosis. ${ }^{19} \mathrm{~A}$ recent observational study showed that compared with a prophylactic anticoagulant, a therapeutic dose of an anticoagulant had the tendency to lower the risk of mortality among hospitalized patients with COVID-19, but it showed an insignificant difference. ${ }^{20}$ In addition, the therapeutic dose was associated with a higher risk of major hemorrhage than was prophylactic dose ( $3 \%$ versus $1.7 \%$ ).

Although case reports are scarce for conclusion, our two cases, in addition to previous reports, suggest that COVID-19 patients treated with anticoagulants are at risk of IPH. The paucity of data on how to balance anticoagulation in COVID19 patients may be attributed to hemorrhagic events. Until randomized trials prove the optimal anticoagulation treatment, there will be no clarity with respect to the ideal type and dose of anticoagulants for patients with COVID-19. If severe flank pain, along with anemia and hypovolemic signs, is present, CT should be used for evaluation.

Received November 24, 2020. Accepted for publication December 29, 2020.

Published online January 13, 2021.

Acknowledgments: We thank the patients and their family members for permitting us to publish this report. The American Society of Tropical Medicine and Hygiene has waived the Open Access fee for this article due to the ongoing COVID-19 pandemic.

Consent for publication: The authors obtained written informed consent for publication of this report from the patients and their family members.
Authors' addresses: Hideta Nakamura, Kazuya Miyagi, Yuuri Higure, Mariko Otsuki, Naoya Nishiyama, Takeshi Kinjo, Masashi Nakamatsu, Masao Tateyama, and Jiro Fujita, Department of Infectious, Respiratory and Digestive Medicine, Graduate School of Medicine, University of the Ryukyus, Okinawa, Japan, E-mails: hnnakamu@med.u-ryukyu.ac.jp, miyagi.kazuya@gmail.com, yr.1129.snvj@gmail.com, owan4x@gmail. com,n.naoyaso@gmail.com, t_kinjo@med.u-ryukyu.ac.jp, massy@ med.u-ryukyu.ac.jp, tateyama@med.u-ryukyu.ac.jp, and fujita@med. u-ryukyu.ac.jp. Gen Ouchi and Ichiro Kukita, Department of Emergency and Critical Care Medicine, Graduate School of Medicine, University of the Ryukyus, Okinawa, Japan, E-mails: genouchi@gmail.com and kukita@med.u-ryukyu.ac.jp.

This is an open-access article distributed under the terms of the Creative Commons Attribution (CC-BY) License, which permits unrestricted use, distribution, and reproduction in any medium, provided the original author and source are credited.

\section{REFERENCES}

1. Zhou F et al., 2020. Clinical course and risk factors for mortality of adult inpatients with COVID-19 in Wuhan, China: a retrospective cohort study. Lancet 395: 1054-1062.

2. Maiese A, Manetti AC, La Russa R, Di Paolo M, Turillazzi E, Frati P, Fineschi V, 2020. Autopsy findings in COVID-19-related deaths: a literature review. Forensic Sci Med Pathol 7: 1-18.

3. Al-Samkari $\mathrm{H}$ et al., 2020. COVID-19 and coagulation: bleeding and thrombotic manifestations of SARS-CoV-2 infection. Blood 136: 489-500.

4. Shah A et al., 2020. Thrombotic and haemorrhagic complications in critically ill patients with COVID-19: a multicentre observational study. Crit Care 24: 561.

5. Llitjos JF, Daviaud F, Grimaldi D, Legriel S, Georges JL, Guerot E, Bedos JP, Fago JY, Charpentier J, Mira JP, 2016. llio-psoas hematoma in the intensive care unit: a multicentric study. Ann Intensive Care 6: 8.

6. Artzner T, Clere-Jehl R, Schenck M, Greget M, Merdji H, De Marini P, Tuzin N, Helms J, Meziani F, 2019. Spontaneous ilio-psoas hematomas complicating intensive care unit hospitalizations. PLoS One 14: e0211680.

7. Patel I, Akoluk A, Douedi S, Upadhyaya V, Mazahir U, Costanzo E, Flynn D, 2020. Life-threatening psoas hematoma due to retroperitoneal hemorrhage in a COVID-19 patient on enoxaparin 
treated with arterial embolization: a case report. J Clin Med Res 12: 458-461.

8. Scialpi M, Russo P, Piane E, Gallo E, Scalera GB, 2020. First case of retroperitoneal hematoma in COVID-19. Turk J Urol 46: 407-409.

9. Erdinc B, Raina JS, 2020. Spontaneous retroperitoneal bleeding coincided with massive acute deep vein thrombosis as initial presentation of COVID-19. Cureus 12: e9772.

10. Guo SH, Zhu SM, Yao YX, 2020. Giant retroperitoneal hematoma during extracorporeal membrane oxygenation in a patient with coronavirus disease-2019 pneumonia. J Cardiothorac Vasc Anesth 34: 2839-2840.

11. Angileri SA, Petrillo M, Meglio LD, Arrichiello A, Roda GM, lerardi AM, Uberoi R, Carrafiello G, 2020. Adverse events in coronavirus disease patients management: a pictorial essay. $J$ Clin Imaging Sci 10: 42.

12. Conti CB, Henchi S, Coppeta GP, Testa S, Grassia R, 2020. Bleeding in COVID-19 severe pneumonia: the other side of abnormal coagulation pattern? Eur J Intern Med 77: 147-149.

13. Bargellini I, Cervelli R, Lunardi A, Scandiffio R, Daviddi F, Giorgi L, Cicorelli A, Crocetti L, Cioni R, 2020. Spontaneous bleedings in COVID-19 patients: an emerging complication. Cardiovasc Intervent Radiol 17: 1095-1096.

14. Valeriani E, Squizzato A, Gallo A, Porreca E, Vincent JL, Iba T, Hagiwara A, Di Nisio M, 2020. Efficacy and safety of recombinant human soluble thrombomodulin in patients with sepsis-associated coagulopathy: a systematic review and meta-analysis. $J$ Thromb Haemost 18: 1618-1625.

15. Doi K, Ikeda M, Hayase N, Moriya K, Morimura N; COVID-UTH Study Group, 2020. Nafamostat mesylate treatment in combination with favipiravir for patients critically ill with COVID-19: a case series. Crit Care 24: 392.

16. Nannoni S, de Groot R, Bell S, Markus HS, 2020. Stroke in COVID-19: a systematic review and meta-analysis. Int $J$ Stroke 1747493020972922. Available at: https://doi.org/ 10.1177/1747493020972922.

17. Cua G, Holland N, Wright $A, 2018$. A difficult situation - balancing critical anticoagulation versus the risk of permanent neurologic deficit: a case report. J Med Case Rep 12: 180.

18. Stattin K et al., 2020. Inadequate prophylactic effect of lowmolecular weight heparin in critically ill COVID-19 patients. $J$ Crit Care 60: 249-252.

19. Chowdhury JF, Moores LK, Connors JM, 2020. Anticoagulation in hospitalized patients with COVID-19. N Engl J Med 383: 1675-1678.

20. Nadkarni GN et al., 2020. Anticoagulation, bleeding, mortality, and pathology in hospitalized patients with COVID-19. J Am Coll Cardiol 76: 1815-1826. 